\title{
TOPONIMIA DEL PARQUE NACIONAL DE DONANA Y SU ENTORNO (HIDRÓNIMOS)
}

\author{
Carmen Castrillo Díaz
}

\section{Introducción.-}

Este artículo se inscribe en un estudio ${ }^{1}$ realizado sobre la toponimia de una zona, aún "inédita", y que se nos presenta especialmente atractiva, dada la diversidad natural y cultural que en ella confluyen. El Parque Nacional de Doñana se halla situado entre las provincias de Huelva y Sevilla, y encajado entre el Océano Atlántico y el río Guadalquivir. La importancia de Doñana como enclave se justifica tanto por sus valores naturales como por ser un lugar cargado de historia y leyenda. El arqueólogo alemán Schulten situó en estas tierras la capital del mítico reino de Tartessos.

Con este artículo pretendemos recoger y analizar desde una perspectiva lingüística el acervo de nombres de lugar del Parque Nacional de Doñana y su entorno que designan cursos de agua y masas de agua estancadas, y que se conocen con la denominación de hidrónimos. Los terrenos que conforman el Parque Nacional de Doñana y su entorno inmediato constituyen una zona de excepcional riqueza hidrológica, lo que se traduce en una importante plasmación toponímica. Dentro de Doñana la planicie marismeña posee unas características hidrológicas propias, originadas por las variaciones ambientales que en ella se producen, y que discriminan marisma seca de húmeda. Este peculiar espacio natural ha configurado un léxico también de excepcionales peculiaridades lingüísticas, con proyección en la toponimia y que recogemos en el apartado de "hidronimia marismeña". En el estudio que hemos llevado a cabo ha sido imprescindible conjugar el análisis puramente lingüístico con el conocimiento de la zona. Por otro lado, la atestiguación documental constituye un complemento de vital importancia para una correcta interpretación etimológica. La labor de documentación toponímica se ha realizado en el Archivo Municipal de Almonte ${ }^{2}$, y en un archivo privado de la localidad ${ }^{3}$.

\footnotetext{
1 Me refiero, en primer lugar, a mi tesis de licenciatura sobre la "Toponimia de Almonte" (Universidad de Sevilla, 1985), que sirvió de base a una investigaión posterior que abarca la zona del Parque Nacional de Doñana y su entorno.

${ }^{2}$ Libros del Catastro del Marqués de la Ensenada. T. II y III (1752) y Amillaramientos o Valuaciones. Legajos 990 y 992 (Segunda mitad del S.XIX).

3 Documentos inéditos pertenecientes al Archivo privado de D.Juan Cepeda (Almonte). Legajo $\mathrm{n}^{\circ} 4$ (15 documentos). Se citan mediante la abreviatura AC.
} 


\section{II.- Corpus hidronímico.-}

ABREVADERO (Abrevadero de Doñana). Procede esta forma de abrevar, mediante sufijación, del latín vulgar *ABBIBERARE, derivado de BIBERE, forma sustantivada del verbo que significa 'beber'4. El uso toponímico de esta voz concuerda con el apelativo 'estanque, pilón o paraje del río, arroyo o manantial a propósito para dar de beber al ganado $^{15}$. Es inusual esta forma en función apelativa en nuestra realidad lingüística (incluso en ciertos sectores se desconoce), por ello viene a ser sustituida en el habla viva por el término sinónimo pilón.

ACEQUIA (Acequia el Molino, Acequia Molino el Cuin). Del árabe s â qu i y a, participio activo del verbo $s$ á $q$ à 'regar' (DCEH,s.v.), que el DRAE define con el significado de 'zanja o canal por donde se conducen las aguas para regar y para otros fines' (s.v., $1^{a}$ ac.). Estos nombres son, hoy, ya parte de un pasado toponímico. El hablante campesino no acierta a precisar el significado de esta voz, desterrada de su léxico habitual y a la cual sustituyen términos como canal o regajo.

AGUA (Aguaciega, Agua de Lázaro, Algaida de las Aguas). El uso de esta voz, del latín AQUA, en el topónimo de forma Agua de Lázaro, viene a sustituir por un procedimiento metonímico al término fuente, adscrita ambas voces al mismo campo semántico. No hay aquí rastro, por tanto, de la antigua acepción de agua 'río o arroyo' (DRAE,s.v., 10 ac.). Aguaciega es compuesto léxico de esa forma y ciega (del latín CAECUM), esta última voz empleada en sentido metafórica a fin de poner de manifiesto la escasez de agua.

ALGAIDA (Algaida de las Aguas, Algaida de Bernabé, Algaida de la Caquera, Algaida del Carrizal, Algaida de la Cierva, la Algaida de Doñana, Algaida de los Naranjos, Algaida de la Osa, Algaida de Pavón, Algaida de Palacio, etc.). Voz de origen árabe, de a $1 \mathrm{~g}$ a i d a 'pantano, cañaveral', 'arboleda en lugar pantanoso', 'soto, bosque' (DCEH,s.v.). El DRAE define este elemento léxico como 'bosque o sitio lleno de matorrales' (s.v., $1^{\text {a }}$ ac.). Ahora bien, su inclusión en este apartado léxico-semántico obedece a los rasgos sémicos peculiares que dicho término adquiere en este ámbito lingüístico. El hablante campesino ifdentifica el término algaida con un 'canal de agua', y establece una comparación entre esta forma y otro de igual carácter hidronímico, regajo (v. p. 248), fundamentada en el tipo de suelo en que éstos se hallen. El significado que adquiere algaida en el habla y la toponimia de Doñana es el de 'caño provisto de abundante vegetación'. En otras localidades onubenses también halla esta forma representación toponímica, aunque en menor intensidad ${ }^{6}$.

Documentación: 1752: Algaida de Bernavé (M. de Ensenada II, fol. 1004). 1849: La Algaida (Amillaramientos, doc.7c).

\footnotetext{
4 J.Corominas-J.A. Pascual, Diccionario Crítico Etimológico Hispánico (Madrid 1982) s.v. beber.

5 Real Academia Española, Diccionario de la Lengua Española (Madrid 1984) s.v. abrevadero.

6 Barranco de la Algaida (Calañas), Las Algaidillas (Niebla), Arroyo Algaidón (Beas). M.P.Noblejas, Repertorio de nombres geográficos. Huelva (Zaragoza 1979) 16.
} 
ARROYO (Arroyo del Algarrobo, Arroyo de Cabezogordo, Arroyo la Calancha, Arroyo de la Carbonera, Arroyo del Corchuelo, Arroyo del Fresnillo, Arroyo del Horcajo, Arroyo del Judio, Arroyo de la Marmoleja, Arroyo de Moriana, Arroyo de la Rocina, Arroyo del Zumajo, etc.). Vocablo hispánico prerromano del masculino correspondiente a arrugia (DCEH,s.v.). Este vocablo halla un empleo muy generalizado en el habla y la toponimia de Doñana, que se corrresponde exactamente con la acepción que el DRAE le otorga 'caudal de agua casi continuo' (s.v., $1^{a}$ ac.). Madoz aporta algunos detalles sobre el curso de los arroyos que bañan el municipio de Almonte: "Ningún río corre por este terreno pero lo bañan diferentes arroyos [...] todos estos arroyos vienen a incorporarse cerca de la Ermita del Rocío [...] y allí se estienden formando en el invierno un gran lago de seis leguas de largo, de $1 / 2$ de ancho que termina en el Guadalquivir"7. A esta lexía se adscriben un importante grupo de topónimos, formados en su mayor parte por un sintagma preposicional que tiene como núcleo nominal un microtopónimo o nombre de lugar menor.

Documentación. 1752: Arroyo de Moriana (M. de Ensenada II, fol. 826). 1859: Arroyo de Moriana (Amillaramientos, doc. 4, $\mathrm{n}^{\circ}$ 601).

CANAliEgA (La Canaliega, Camino de la Canariega, Casa de la Canariega, Puente de la Canaliega). Esta voz es un derivado de canal, del latín CANALIS (DCEH,s.v.canal). El DRAE registra esta forma como voz anticuada, con el significado de 'canal, teja más combada que las otras' (s.v., $1^{\mathrm{a}}$ ac.). El sentido toponímico de este vocablo se ajusta a la definición 'canal de pesquerías', de modo que cuadraría perfectamente con la historia del lugar, antigua zona de pesquería interior. El sitio llamado hoy Canaliega o Canariega fue conocido en otro tiempo con el nombre de Charcos del Perchel, denominación que viene a apoyar el valor semántico que para esta voz hemos dado. Perchel designa un 'aparejo de pesca', y por tanto en estrecha conexión con las abundantes pesquerías que se llevaban a cabo en estos parajes ${ }^{8}$. Confirma el sentido de Canaliega la atestiguación documental de 1459, donde dicho vocablo presenta los mismos contornos semánticos: "Antonia Gómez, mujer que fue de Felipe Martínez, se querella contra Fernando de Zurita, que le había quitado la posesión de una canaliega de pesquería que ella tenía en el río Guadiamar, término de Aznalcázar"9.

La preocupación por descubrir la significación primitiva y por tanto, el origen de los nombres de lugar ha existido desde siempre. Cualquier persona se siente capacitada para hacer disquisiciones e hipótesis toponímicas de donde surgen descabelladas etimologías. Es el caso de los topónimos adscritos a este tipo léxico. Así, según la tradición popular el lugar de nombre la Canaliega o Canariega procede de canal griega. El fenómeno de la

\footnotetext{
7 P.Madoz, Diccionario geográfico-estadístico-histórico de España y sus posesiones de Ultramar (Madrid 1840), t.II, 172.

8 " Las anguilas, otra de las especies marismeñas, permanecen en el fango y constituyen, junto con las tencas y los galápagos las pesquerías de lagunas y charcas, entre las que destaca Santa Olalla, la Dulce y el Perchel o Canaliega; arrendada esta última por el Concejo almonteño no sólo para estas pesquerías sino también para la captura de sanguijuelas con fines medicinales ". J.F.Ojeda Rivera, Organización del territorio en Doñana y su entorno próximo (Almonte). S.XVIII-XX (Madrid 1987) 56.

9 Esta cita me la facilitó D.Juan Infante Galán y procede de una notas extraídas del Archivo Catedralicio de Sevilla (Octubre-Diciembre, 1459) fol. 87.
} 
etimología popular es un equívoco muy frecuente en la toponimia, al pretender buscar el pueblo una explicación asequible a ciertos nombres de lugar semánticamente opacos. De ello deducimos, pues, la necesidad de poseer especiales conocimientos lingüísticos para hacer investigación toponímica.

CHARCO (Charco de la Cañada, Charco del Acebrón, Charco de la Isla, Charco de Juan Rivas, Charco la Nutria, Charco del Toro, Los Charcones, etc.). Esta voz, común al castellano y al portugués, es de origen desconocido, quizá prerromano (DCEH,s.v.). Su empleo toponímico coincide con el significado de este término en el habla común 'agua detenida en un hoyo o cavidad de la tierra o del piso' (DRAE,s.v., $1^{\mathrm{a}}$ ac.).

Documentación. 1752: Charco de Juan Rivas (M. de Ensenada I, fol. 10). 1849: Charco de Juan Rivas (Amillaramientos, doc. 7cc).

CHORRO (Chorrito Bajo, Fuente del Chorrito). Onomatopeya de la caída del agua: la acepción originaria parece que fue 'agua que salta en cáscada o torrente', y es voz común al castellano con el portugués, el vasco y el gascón (DCEH,s.v.), con el sufijo diminutivo -ito. Señala Corominas la intensa proyección toponímica de chorro en todas las tierras de lengua castellana. La toponimia onubense refleja igualmente el empleo generalizado de esta voz de carácter hidronímico, abundando en sobremanera las formas sufijadas en -ito ${ }^{10}$.

FUENTE (Fontidueña, Fuente del Cochino, Fuente de la Pañuela, Fuente de los Romeros, Fuente de Sancho Mingo, Fuente la Teja, Fuente de los Tiradores, Fuente de la Zorra, etc.). Halla esta forma su étimo en el latín FONS, FONTIS. Identificamos esta lexía en la toponimia con la diptongación característica del castellano, junto a la variante arcaica, donde la vocal breve y abierta $o$ no está diptongada. Es el caso del microtopónimo, hoy perdido, Fontidueña, composición toponímica que tiene su origen en el latín FONTEM DOMINAM. Estas formas toponímicas nacieron por analogía a aquellas otras composiciones antiguas donde los dos elementos formantes evolucionaron como una sola palabra, con retrotracción del acento al segundo término de la composición ${ }^{11}$. Frente a este hecho excepcional abundan las formas diptongadas seguidas de un complemento preposicional.

Documentación. 1763: Padrón de Fontidueña (AC, doc. 11.2). 1850: Fuente de la Teja (Amillaramientos, doc.8).

GOLA (Gola del Dinero). El topónimo de esta forma presenta la variante fonética gola, con la introducción de la velar $g$ en apoyo de la vocal silábica inicial. La voz de la cual se deriva, ola, es de origen incierto; probablemente se tomara del árabe $h a ́$ u l a 'remolino', $h$ á u l 'agitación del mar, tormenta' (DCEH,s.v. ola). En los pueblos del entorno de Doñana, el término gola se usa con el significado de 'zona baja de la playa que queda inundada al bajar la marea', de acuerdo con su empleo toponímico, y no coincide con ninguna de las

\footnotetext{
10 Fuente del Chorro (Villablanca), Majada del Chorrito (Aracena), Chorrito Alto (Huelva), Chorrito Ramón (Cortelazor). Noblejas, 1979:64-65.

11 A.Montenegro Duque, " Toponimia Latina ", Enciclopedia Lingüística Hispánica (Madrid 1960), t. I, 515.
} 
acepciones que el DRAE cita para esta forma. El ALEA registra esta misma voz en Málaga y en Chipiona (Cádiz) con distinta acepción 'duna o montecillo de arena junto al mar'12.

GUAD- (Caño Guadiamar, Marismas del Guadalquivir, Río Guadalquivir). Formante hidronímico que delata un origen árabe ( $W a d i$ 'río'), muy frecuente en composiciones toponímicas que designan nombres de ríos. La composición léxica Guadalquivir deriva del árabe $W a d i-a l-k a b i r$.

ISLA (La Isleta, Charco la Isla, Camino de la Isleta). Este vocablo, general en todas las épocas y común a todos los romances, procede del latín INSULA, con el sufijo diminutivo -eta. Los lugares que estos topónimos designan se hallan cercados por dos arroyos.

Documentación. 1752: Citio de la Hisla (M. de Ensenada I, fol. 382). 1752: La Isleta (M. de Ensenada I, fol.401). 1859: Isleta (Amillaramientos doc. 4, n 72).

LAGO (Lago de la Rocina, Lago Porquera Barrera). Del latín LACUS 'balsa', 'depósito de líquidos', 'estanque', 'lago' (DCEH,s.v.); es otra de las formas de la topografía descriptiva que nos proporciona el latín.

LAGUNA (Laguna del Acebuche, Laguna del Aguardo, Laguna Carrizosa, Laguna del Contrabandista, Laguna de Frayguán, Laguna del Jorcón, Laguna de los Monteruelos, Lagunas del Río Loro, Laguna de Santa Olalla, etc.). Procede de la forma latina LACUNA 'hoyo, agujero', derivado del latín LACUS, (DCEH,s.v. lago). La diferencia semántica de esta voz con la forma lago, de su misma familia léxica, queda establecida por las dimensiones de estos cursos de agua. El significado que el DRAE concede a este término es el de 'depósito natural de agua, generalmente dulce y por lo común de menos dimensiones que el lago' (s.v., $1^{a}$ ac.). Forma muy usual en la toponimia de Doñana, así lo evidencian un numeroso grupo toponímico. Dentro de la zona que corresponde al actual Coto de Doñana, queda como recuerdo de la influencia marina y fluvial que llenaban estos parajes un rosario de lagunas en dirección al mar, entre ellas la más importante "la nombrada Santa Olalla o La Pajarera, que tiene de circunferencia 3/4 de legua: es abundante de varias clases de peces y aún más de aves acuáticas..." (Madoz 1840,t.II, 172).

MAR (Camino de la Mar, Laguna de la Mar). Del latín MARE. En función hiperbólica en el topónimo de nombre Laguna de la Mar, para poner de manifiesto su abundante depósito de agua.

Documentación. 1752: Camino de la Mar (M. de Ensenada I, fol. 65). 1856: Camino de la Mar (Amillaramientos, doc. 2, $\mathrm{n}^{\circ}$ 143).

POZO (El Pocito, Pozo del Alto de la Ruda, Pozo de la Dehesilla, Pozo Matalagrana, Pozo del Puntal, Pozo de los Republicanos, Pozo de las Salinas, Los Pozuelos, etc. Esta voz tiene su arranque etimológico en el latín PUTEUS 'hoyo', 'pozo' (DCEH,s.v.), aparece también sufijada (-ito, - uelo). A esta familia léxica se adscriben también las formas: poza 'pilón subterráneo de grandes dimensiones para almacenar aceite o vino', pozanco ' depósito

12 T.Garulo, Los arabismos en el léxico andaluz (Madrid 1983) 110. 
de agua de escasa profundidad situado a ras del suelo con un rudimentario sistema de extracción del agua'.

Documentación. 1687: pozo que llaman de las huertas (AC, doc. 1). 1752: los Pozuelos (M. de Ensenada I, fol. 772). 1859: los Pozuelos (Amillaramientos, doc. 4, nº 71).

REGAJO (Regajo de los Abuelos, Regajo de Calancha, Regajo de los Calvos, Regajo Culantrillo, Regajo de la Lantisquilla, Regajo de los Pajares del Conde, Regajo de la Parrada, Regajo de la Puentezuela, Regajo del Zaillo, etc.). Es un derivado de regar, del latín RIGARE 'regar, mojar'. El empleo del término regajo 'charco que se forma de un arroyuelo' (DRAE s.v., $1^{\mathrm{a}}$ ac.) se halla generalizado de forma extraordinaria en función toponímica y apelativa. La construcción de regajos en suelos cultivados se hace con objeto de " sanear " las tierras, a fin de evitar su posible encharcamiento. Con la llegada del verano el agricultor procede a " alumbrarlos ", esto es, a despojarlos de malezas y " tropezones " (zarzas. ramas de olivo, troncos), para facilitar así el paso de las aguas. El abundante uso de esta forma, pues, en la toponimia rural se halla en íntima relación con la intensa actividad agrícola que siempre caracterizó a estos lugares. P.Noblejas recoge en diversos municipios onubenses topónimos adscritos a este elemento léxico ${ }^{13}$.

Documentación. 1752: Regajo de la Parrilla (M. de Ensenada I, fol. 413). 1860: Regajo de la Parrilla (Amillaramientos, doc. 5, n 641).

\section{II.1.- Hidronimia marismeña.-}

CAÑ̃ (Caño de Brenes, Caño de la Figuerola, Caño Marín, Caño de la Venta, Arroyo de Caño Marín, etc). Formación masculina del español y portugués, derivada del latín CANNA (DCEH,s.v. caña). No concuerda su empleo en la toponimia con la acepción que el DRAE le otorga 'chorro de agua que cae por una parte estrecha' (s.v., $1^{a}$ ac.). El uso toponímico de esta forma en parajes marismeños se corresponde con el significado de 'cauces de agua que cruzan las zonas de marisma'. Observamos la estrecha conexión semántica de esta denominación con el significado que para ella registra J.A. de Armas en Venezuela ' corriente arremansada o no de cierta hondura, común en el Llano'14.

Documentación. 1854: Caño de la Figueroa (Amillaramientos, doc. 1, $\mathrm{n}^{\circ}$ 1048).

LUCIO (Lucio de los Ansares, Lucio Boyero, Lucio del Membrillo, Lucio de los Ojillos Salados, Lucio Pelón, Lucio de Vetalengua, etc.). Restos de una zona lacustre son estas formaciones hidrológicas típicas del paisaje marismeño, los llamados lucios. Procede esta voz del latín LUCIDUS 'brillante', 'luminoso', derivado del latín LUX, LUCIS (DCEH,s.v. luz), que el DRAE registra con la siguiente acepción: 'Cada uno de los

\footnotetext{
13 Arroyo Regajo de los Soldados (Rociana), Arroyo los Regajos (Los Marines), Cortijo Regajuelos (Valdelarco). Noblejas 1979:172.

14 J.A. de Armas Chitty, Vocabulario del Hato (Venezuela 1966).
} 
lagunajos que se quedan en la marisma al retirarse las aguas' (s.v., $2^{\text {a }}$ ac.). El lucio adquiere tal denominación por ser lugares resplandecientes ${ }^{15}$.

MADRE (Madre de las Marismas del Rocío, Arroyo de las Madres, Regajo la Madrecilla). La forma latina MATER, MATRIS contiene una proyección hidronímica, pues se aplica para designar cursos de agua importantes. En efecto, La Madre en estos lugares llamada comúnmente así o Madre de las Marismas del Rocío, cruza toda la marisma almonteña, desde la aldea del Rocío hasta la desembocadura del Caño de Brenes. En la zona sur de Andalucía tenemos: Arroyo de la Madre en Granada, Arroyo de la Madre Vieja en Cádiz $^{16}$, y en diversas localidades de la provincia de Huelva ${ }^{17}$.

Documentación. 1772: Arroyo de las Madres (AC, doc. 9).

MARISMA (Marisma de Doñana, Marismas del Rocío, Madre de las Marismas del Rocío, Las Marismillas, etc.). Forma procedente del latín MARITIMA 'costa del mar' (DCHE,s.v. mar), con el sufijo diminutivo -illa. El DRAE define este vocablo con el significado de 'terreno bajo y pantanoso que se inunda con las aguas del mar' (s.v., $1^{\circ}$ ac.). El sustantivo femenino marisma no se ha mostrado improductivo en el vocabulario geográfico español. P.Aebischer localiza el empleo toponímico de esta voz, entre otros lugares, en el litoral sur y oeste español: " La región situada sobre el golfo de Cádiz, entre Sevilla y el Océano, es conocida aún hoy con el nombre de las Marismas "18. El pueblo de Almonte incluye en su término una porción de las extensas marismas del Guadalquivir, que vinculada a este río y a su arroyo de la Madre del Rocío, cruza el límite oriental del pueblo, desde la aldea del Rocío hacia el suroeste. También Madoz alude a la marisma de Almonte señalando que es " tan llano y tan apacible su curso que apenas se conoce " (pag.72).

Documentación. 1752: la marisma (M. de Ensenada I, fol.718).

OJO (Ojo de las Aneas, Ojo de Cabrera, Ojo del Cornejo, Ojo de Pedro Arco, Ojuelos, Laguna Ojuelos, etc.). Del latín OCULUS, con el diminutivo romance -uelo. Voz incluida en el campo hidronímico por su acepción metafórica 'manantial que surge en un llano' (DRAE,s.v. $8^{\mathrm{a}}$ ac.). Observa Corominas que el uso de esta forma con la acepción que aquí nos ocupa es tan antigua en castellano como en la lengua literaria, pues ya la encontramos en la General Estoria donde se habla de una ciudad construida " entre los ojos de los manantiales del Nilo" (DCEH,s.v.). El uso toponímico y apelativo de esta voz para designar metafóricamente estos manantiales, alcanza extraordinaria vigencia en Doñana. En su descripción de la marisma de Almonte, Madoz hace referencia a " unos sitios llamados Ojos, que son unos viveros de agua insondables, encubiertos de musgo, que lo hacen parecer de sólido suelo, el ganado tiene instinto particular para evitarlos " (Pag. 172). Este término

15 " En junio, en años normales, son los únicos lunares de agua de la marisma; el agua se evapora y deposita sales en su fondo que en agosto, seco ya el lucio del todo lo hacen espejear al sol ". A.Duque, El Mito de Doñana (Madrid 1977) 65.

16 V.García de Diego, Toponimia de la zona de Jerez de la Frontera (Jerez de la Frontera 1972) 10-11.

17 Arroyo de Madre del Agua (San Bartolomé de la Torre), Casa Nueva de la Madre del Agua (Villanueva de los Castillejos), Laguna de las Madres (Moguer, Palos de la Frontera), Canal de las Madres (Cartaya). Noblejas, Zaragoza 1979:102.

18 P.Aebischer, Estudios de toponimia y lexicografía románicas (Barcelona 1948) 88. 
se halla muy disperso por toda España, particularmente en la toponimia, pero también se muestra vivo como apelativo. En otras zonas de Huelva aparecen también topónimos adscritos a esta forma léxica ${ }^{19}$.

ZACALLÓN (Zacallón de Cabrera, Zacallón Grande, Zacallón de Socorro, Zacallón de Pedro Arco, etc). El término zacallón es una variante popular de azacaya, con aféresis y el sufijo aumentativo -ón. Azacaya es una voz de origen árabe que procede de $s$ i q â y a 'conducto de aguas', 'depósito, abrevadero', y significa 'ramal o conducto de agua' (DRAE,s.v. $2^{\mathrm{a}} \mathrm{ac}$.). En el área lingüística de Doñana y su entorno se utiliza en función toponímica y apelativa con este mismo sentido, y se aplica a un 'conducto de aguas provenientes de un ojo, donde el ganado abreva'. La acepción antigua 'noria grande' (DRAE,s.v. $1^{\mathrm{a}}$ ac.) de azacaya no encuentra correspondencia en el habla ni en la toponimia de este lugar. El aporte documental muestra esta voz con distintas variantes fonéticas.

Documentación. 1752: Acallón (M. de Ensenada II, fol. 1195). 1763: Asacayón (AC, doc. 7.3). 1849: Azacayón (Amillaramientos, doc. 7C).

La disparidad natural y cultural del Parque Nacional de Doñana ha originado una variada gama de denominaciones que alcanzan representación en otros dominios, como es el campo de la orografía, vías de comunicación, edificaciones, hagiotoponimia, fauna y flora, relieves, aspectos históricos, etc., y que constituyen un potencial toponímico que he analizado en estudios posteriores, y en otros que, en la actualidad, se hallan en vía de desarrollo.

19 Ojo (Beas), Barranco del OJO (Beas, Paterna dcel Campo), Barranco de los Ojos (Paymogo). Noblejas, 1984:126. 